\title{
A difficult decision
}

\section{Norbert Gleicher}

Accepted: 5 September 2006 / Published online: 10 January 2007

(C) Springer Science + Business Media, LLC 2007

Keywords Medical journal $\cdot$ Publication · Editor · Ethics · Review Process

What is a journal editor to do if during the review process of a manuscript the technical competence of the laboratory is called into question? An incompetent laboratory, of course, will report inaccurate results. Any study, based on such results, in turn, will reach the wrong conclusions and be misleading. Assuming that a laboratory's incompetence has been confirmed, an editor's responsibility then is clear; such a manuscript has to be rejected.

However, how does one confirm (or, indeed, refute) the alleged technical incompetence of a laboratory?

What is an editor to do if, during the review process of a manuscript, authors are accused of (to paraphrase) "bad will," and of "previously having attempted to tear down others' work," with the implication being that, consciously or subconsciously, the data may not be factual. The confirmation of, for whatever reason, manipulated data, of course, will lead to the paper's rejection.

However, how does one, under such circumstances, confirm (or, indeed, refute) such an accusation?

Any editor has to consider such accusations (and others, which may cross his/her desk) seriously. After all, they come from carefully selected experts, chosen for their expertise, and intimate familiarity, with subject and, yes, colleagues in their respective areas of work. ${ }^{1}$ Reviewers, like all of

\footnotetext{
N. Gleicher $(\square)$

Editor-in-Chief

e-mail: ngleicher@thechr.com

${ }^{1}$ While authors are mostly unaware who reviews their manuscripts (this Journal offers reviewers to reveal themselves, though less than 2\% have historically chosen to do so), reviewers at JARG do know who the authors are. Whether this kind of asymmetry in anonymity is fair and
}

us, are, however, not always perfect in their judgments. Indeed, it seems reasonable to assume that some, whether consciously or subconsciously, may reach unfair conclusions, which then are reflected in their comments to the editor. Especially, when reviews stray from criticism of factual details into the realm of personal innuendo, as above two examples so amply demonstrate, editors are often left with difficult decisions.

The review of manuscripts is never a simple process. It takes considerable time and effort to offer honest and detailed opinions. Good reviewers are in high demand. It, indeed, has almost become self-defeating to be a good reviewer, as the number of requests for (usually unpaid) reviews is increasing with growing numbers of new (now often webbased) medical journals. We editors, therefore, honor and appreciate our reviewers to a considerable degree and are constantly attempting to recruit new ones.

A small number of recent research scandals, which have attracted considerable public attention, have further complicated the review process. Editors have become more cautious in acceptance of manuscripts and encourage a higher degree of suspicion in their reviewers. Nobody can, therefore, be surprised that more innuendo may have entered the review process, as reviewers are caught up in their editor's demands for caution and skepticism, while editors are expected (by media and public) to add the abilities of a scientific detective to their multitude of other responsibilities.

represents the best format of peer review has remained controversial [1], though a large majority of medical journals currently follow such a policy and only a minority choose to blind authors as well as reviewers. Most studies on the subject have suggested that the blinding of either authors or reviewers does not significantly impact the quality of the peer review process [2]. 
The two above described examples of innuendo are not theoretical. They, indeed, converged in the review process of one manuscript (to remain anonymous), which, after careful considerations, was accepted and appears in print in this issue of JARG. It presented our editorial office with difficult decisions, further complicated by the authors' (voluntary) disclosure that their manuscript had been previously rejected by two other prominent journals, based on similar comments during the review process.

An editorial office, of course, is not in a position to assess the quality of a laboratory or the integrity of a research process. The former is the obvious function of accreditation bodies, while the latter remains the institutional responsibility of the research location. Journals, however, can verify whether a laboratory follows standard guidelines and maintains an appropriate quality assurance process and whether data documentation has been maintained appropriately during data collection. As part of the manuscript revision process, the authors were, therefore, in this case asked to submit to the editorial office evidence in support of proper laboratory procedures.

Their existence, of course, does not prove the professional competence of the laboratory or the scientific integrity of the whole study project. However, there are, in our opinion, limitations how far an editorial investigation can, and should, go, without appearing as arbitrary and unfair to authors.

As the responsible editor I personally also reviewed the authors' prior literature on the subject and was unable to find support for their alleged biases towards the work of others. I, therefore, decided, based on my best judgment of the moment, to accept the manuscript for publication. Only time will tell whether this was the right decision. It seemed, however, the correct decision for the moment-the fair decision.
It is widely recognized that the review process is anything but perfect $[1,2]$. Those who submit and those who accept manuscript have known this for a very long time. As somebody who finds himself regularly on both sides of this divide (for obvious reasons, I do not submit my own research to this Journal) I have, however, come to wonder whether the process hasn't become too difficult and complex and whether expectations are not exceeding possible realities.

Truth in science has always been relative, requiring, often repeated, confirmation of findings before they are accepted as "true." Scientists, better than most others, also understand that, what represents truth today may be outdated by the discoveries of tomorrow. In the end, scientific truth will, however, always prevail.

Sometime in the not too distant future we all will know whether the paper published in this issue of JARG, which spurned this editorial did indeed contribute to medical knowledge — or was simply the product of a poor quality science. Our continuous, and ongoing, search for the ultimate scientific truth is, after all, one of the most exhilarating features of being a member of the scientific community. By having published this paper, we feel that we have contributed to this process. And isn't this the principal function of a medical journal?

\section{References}

1. Smith J Jr, Nixon R, Bueschen AJ, Venable DD, Henry HH 2nd. Impact of blinded versus unblinded abstract review on scientific program content. J Urol 2002; 168:2123-5

2. Godlee F, Gale CR, Martyn CN. Effect on the quality of peer review of blinding reviewers and asking them to sign their reports: a randomized controlled trial. JAMA 1998; 280:237-40 